\title{
Construction of functional porphyrin polystyrene nano-architectures by ATRP $\dagger$
}

\author{
Femke de Loos, Irene C. Reynhout, Jeroen J. L. M. Cornelissen,* Alan E. Rowan* and Roeland J. M. Nolte \\ Received (in Cambridge, UK) 5th August 2004, Accepted 3rd November 2004 \\ First published as an Advance Article on the web 1st December 2004 \\ DOI: 10.1039/b412067a
}

A series of mono-functionalized metallo-porphyrin polystyrenes have been synthesized using atom transfer radical polymerization and their self-assembling behavior was studied by electron microscopy showing that the polystyrene tail-length influences the aggregate architecture.

The construction of well-defined functional nano-objects is nowadays one of the main topics in supramolecular chemistry. The use of porphyrins as components of the nano-system is of interest since they may introduce functional properties such as energy transfer and catalysis. To construct such porphyrin-functionalized nanostructures we decided to prepare amphiphilic porphyrins, since these can be expected to self-assemble into a large variety of structures. Small molecular weight amphiphilic porphyrins have already been shown to assemble into interesting architectures. ${ }^{1}$ The need to increase the stability of the aggregates prompted us to develop polystyrene-based porphyrin amphiphiles. Polymeric amphiphiles, for example block copolymers, are known to assemble into various (kinetically) stable structures. ${ }^{2}$ Our goal is to control the aggregate morphology by adjusting the ratio between the polar and apolar part of the amphiphile and thereby influence the functionality of the aggregated system. To this end, we have utilized atom transfer radical polymerization (ATRP) to construct porphyrin-functionalized polystyrenes. ATRP is a rather well established polymerization process, allowing good control over the degree of polymerization and chain length distribution., Recently, Beil and Zimmerman have used ATRP in combination with a porphyrin complex to perform polymer imprinting. ${ }^{5}$

We prepared a series of ATRP initiators, all based on a mono initiator-functionalized tritolylporphyrin, which differ in porphyrin inner-core functionalization. Scheme 1 depicts the synthesis of the free-base porphyrin initiator $\mathbf{2 a}$, the copper porphyrin initiator $\mathbf{2 b}$, the manganese porphyrin initiator $\mathbf{2 c}$ and the zinc porphyrin initiator 2d. With these initiators we performed bulk-polymerization reactions of styrene under ATRP conditions (Scheme 1) $\$$

Polymerization of styrene with free-base initiator $\mathbf{2 a}$ did not take place with one equivalent of copper, due to preferential insertion of copper(II) into the porphyrin core. UV-vis spectroscopy showed that this insertion was already complete after the first $15 \mathrm{~min}$ of the reaction. ${ }^{6}$ As a result, no $\mathrm{Cu}(\mathrm{II})$ was left to be converted into $\mathrm{Cu}(\mathrm{I})$ to enter the catalytic cycle. However, both with two and ten

$\uparrow$ Electronic supplementary information (ESI) available: ATRP procedure and characterization data. See http://www.rsc.org/suppdata/cc/b4/ b412067a/

*j.cornelissen@science.ru.nl (Jeroen J. L. M. Cornelissen)

a.rowan@science.ru.nl (Alan E. Rowan) equivalents of copper, polymerization did take place (Fig. 1). Using 2 equivalents of copper bromide the polymerization progressed in a controlled fashion resulting in polystyrenefunctionalized $\mathrm{Cu}$ (II)-porphyrin with low polydispersity, as was confirmed by GPC (Table 1 and Fig. 2a) and MALDI-TOF mass spectrometry. When 10 equivalents of copper bromide were used GPC showed that the formed polystyrene had a much higher molecular weight than expected. Also, a low molecular weight peak was observed, which had a strong absorption at $420 \mathrm{~nm}$ pointing to the presence of a high concentration of free porphyrin. Probably, the large amount of copper leads to the cleavage of the ester bond between the porphyrin and the growing polymer chain. This alters the initiator : monomer ratio in favour of high molecular weight polymer. Another possible explanation is that

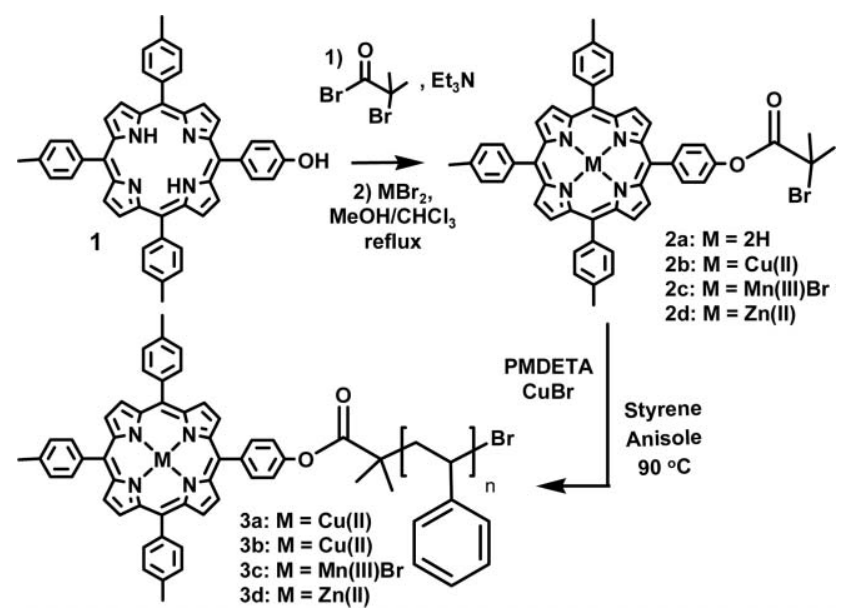

Scheme 1 Synthesis of porphyrin-functionalized polystyrene.

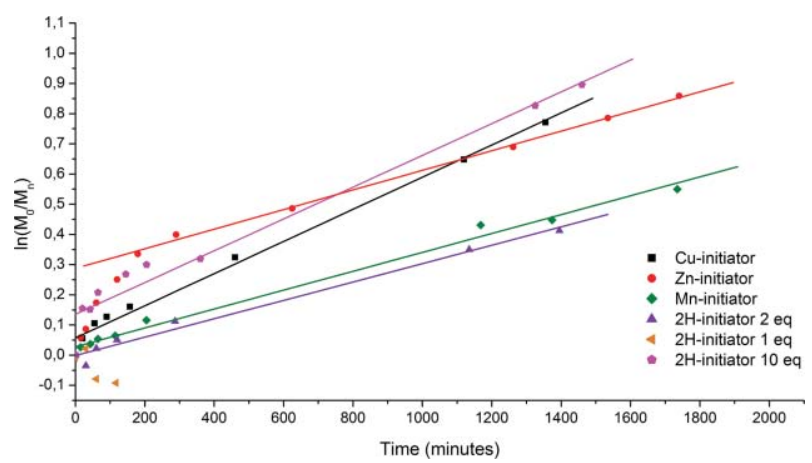

Fig. 1 First order log plots of the conversion of styrene as a function of time for the polymerization of styrene with porphyrin initiators $\mathbf{2 a - 2 d}$. 
Table 1 Polymerization conditions and characterisation of polystyrene compounds

\begin{tabular}{|c|c|c|c|c|c|}
\hline Initiator & Polystyrene product & Polymerisation conditions & $\mathrm{PDI}^{a}$ & $M_{\mathrm{n}} / \mathrm{kg} \mathrm{mol}^{-1 a}$ & $M_{\mathrm{w}} / \mathrm{kg} \mathrm{mol}^{-1 a}$ \\
\hline $2 \mathbf{a}$ & 3a (2 equiv.) & 2 equiv. $\mathrm{CuBr}, 2$ equiv. PMDETA ${ }^{b}$ & 1.39 & 5.8 & 8.0 \\
\hline $2 \mathbf{a}$ & 3a (10 equiv.) & 10 equiv. $\mathrm{CuBr}, 20$ equiv. PMDETA $^{b}$ & 1.28 & 16.0 & 20.0 \\
\hline 2b & $3 \mathbf{b}$ & 1 equiv. $\mathrm{CuBr}, 2$ equiv. PMDETA $^{b}$ & 1.22 & 4.2 & 5.2 \\
\hline $2 \mathrm{c}$ & $3 c$ & 1 equiv. $\mathrm{CuBr}, 2$ equiv. PMDETA $^{b}$ & 1.57 & 3.9 & 6.2 \\
\hline 2d & 3d & 1 equiv. $\mathrm{CuBr}, 2$ equiv. PMDETA $^{b}$ & 1.14 & 3.6 & 4.2 \\
\hline
\end{tabular}
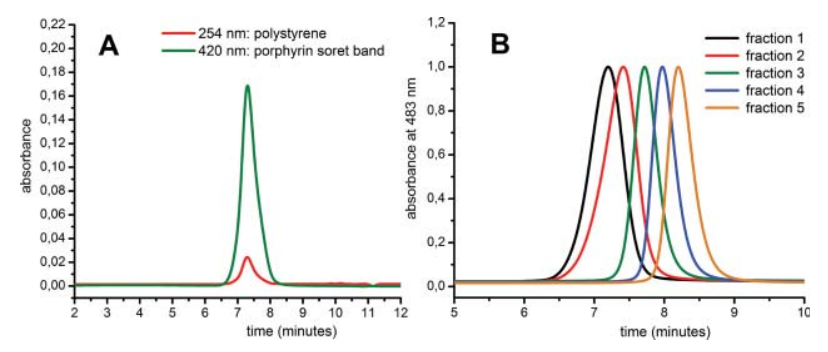

Fig. 2 (A) GPC-traces of $\mathrm{Cu}$-porphyrin polystyrene measured at two different wavelengths, $254 \mathrm{~nm}$ (polystyrene), $420 \mathrm{~nm}$ (Cu-porphyrin). (B) GPC-traces $(254 \mathrm{~nm})$ of $\mathrm{Mn}$-porphyrin polystyrene fractions collected after size exclusion column.

the increase in $\mathrm{Cu}(\mathrm{I})$ concentration results in an increased number of radicals at the start of the polymerisation and hence to an increase in termination reactions. When $\mathrm{Cu}$-porphyrin $\mathbf{2 b}$ was applied as the initiator, 1 equivalent of $\mathrm{CuBr}$ proved to be sufficient to perform a controlled polymerization, as expected.

In order to construct amphiphilic polystyrenes with catalytic properties polymer $\mathbf{3} \mathbf{c}$ was prepared from initiator $\mathbf{2} \mathbf{c}$ having a positively charged manganese headgroup. The Mn(III)-porphyrinpolystyrene $3 \mathbf{c}$ showed a relatively high polydispersity of 1.5 .

Only a limited number of metals inside the porphyrin catalyst can be used, since these metals may interact with the copper catalyst. The use of free-base initiator followed by insertion of the metal after polymerization is not an option due to insertion of copper during the polymerization of styrene. In addition, the copper is difficult to remove from the porphyrin core and will result in decomposition of the macromolecule. We decided therefore to synthesize $\mathbf{Z n}$-porphyrin-polystyrene $\mathbf{3 d}$. Zinc is easily removed from the porphyrin in this compound under mild acidic conditions. This will give the possibility to insert any metal after the polymerization reaction. The polymerization of styrene from the $\mathbf{Z n}$-porphyrin initiator $\mathbf{2 d}$ was performed in a similar controlled fashion yielding a $\mathrm{Zn}$-porphyrin-polystyrene with low polydispersity (Table 1).

For the free-base porphyrin initiator with 2 equivalents of $\mathrm{CuBr}$ as well as for all three metallo-porphyrin initiators the conversion of styrene in time showed first-order kinetics (Fig. 1). The rate constants varied from $5.1 \times 10^{-6} \mathrm{~s}^{-1}$ to $8.9 \times 10^{-6} \mathrm{~s}^{-1}$, depending on the initiator that was used.

The aggregation behavior of the $\mathrm{Cu}$-porphyrin-polystyrene prepared with 2 equivalents of $\mathrm{CuBr}$ (3a) was studied in water. When the porphyrin-functionalized polystyrene was injected from a THF-solution into water while sonicating at $60{ }^{\circ} \mathrm{C}$, highly monodisperse $(\mathrm{DI}=1.02)$ micellar structures, $20-35 \mathrm{~nm}$ in size, were formed (Fig. 3a). In subsequent experiments, the aggregation behavior of the Mn-porphyrin-polystyrene was investigated. 3c

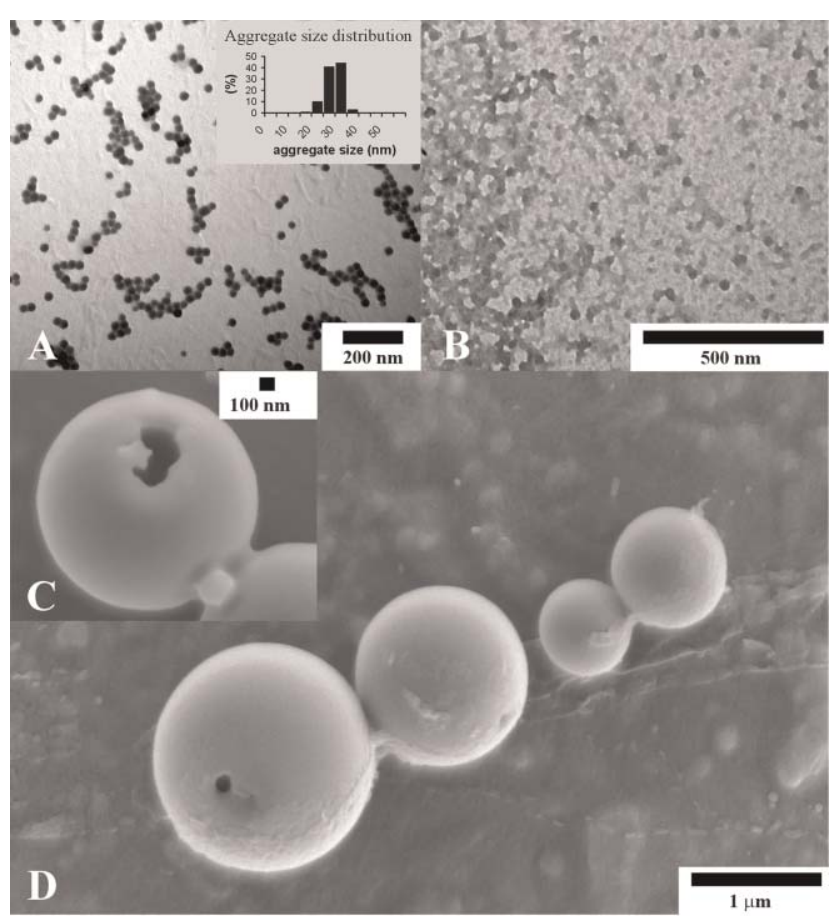

Fig. 3 (A) and (B) Transmission electron micrographs of the aggregation behaviour of amphiphilic $\mathrm{Cu}$-porphyrin-polystyrene (A) and $\mathrm{Mn}-$ porphyrin-polystyrene $M_{\mathrm{n}}=9973$ (B). (C) and (D) Scanning electron micrographs of the aggregation behaviour of $\mathrm{Mn}$-porphyrin-polystyrene with $M_{\mathrm{n}}=1495$.

was fractionated in different samples (f1-f5) with $M_{\mathrm{n}}$ 's ranging from 1495 to 9973 and polydispersities ranging from 1.09 to 1.27 (Fig. 2b). With two of these fractions, f1 $\left(M_{\mathrm{n}}=9973\right.$, PDI $=1.24)$ and $\mathbf{f 5}\left(M_{\mathrm{n}}=1495, \mathrm{PDI}=1.11\right)$, aggregation studies were performed. For the more hydrophilic Mn(III)-porphyrinpolystyrene, sonication was not required to obtain well defined architectures. The polymer was dissolved in THF and water was slowly added until the solution turned cloudy. TEM studies showed the formation of small spherical micellar aggregates for f1 (Fig. 3b). The Mn(III)-porphyrin-polystyrene with the shortest apolar tail (f5), showed the formation of large spherical architectures $0.5-2 \mu \mathrm{m}$ in size, which are vesicular-like in nature. SEM studies showed that these structures are porous, suggesting they are hollow spheres (Fig. 3c and 3d). In the case of f5 the average length of the apolar tail is comparable to the diameter of the porphyrin head (estimated from calculations). However, for f1, the length of the polystyrene tail is ten times larger. The difference in the ratio head : tail results in a different aggregation behavior. The structures proved to be stable over time for at least one month. 
In summary, it is shown that the polymerization of styrene by ATRP using a series of metallo-porphyrin initiators proceeds in a controlled fashion and yields well-functionalized metallo-porphyrin polystyrenes with low polydispersities. The $\mathrm{Cu}$-porphyrin-polystyrene (3a) formed well defined highly monodispersed spheres in water. Aggregation studies of the $\mathrm{Mn}-$ porphyrin-polystyrene (3c) showed that the morphology of the architectures formed in water was controlled by the polystyrene tail length. Currently we are investigating the catalytic properties of the different $\mathrm{Mn}(\mathrm{III})$-porphyrin-polystyrene architectures.

The Council for the Chemical Sciences of the Netherlands Organization for Scientific Research is acknowledged for financial support to R. J. M. Nolte (TOP grant), J. J. L. M. Cornelissen (Veni grant) and A. E. Rowan (Vidi grant).

Femke de Loos, Irene C. Reynhout, Jeroen J. L. M. Cornelissen,* Alan E. Rowan* and Roeland J. M. Nolte

Department of Organic Chemistry, Institute for Molecules and Materials (IMM), Radboud University Nijmegen, Toernooiveld 1, 6525 ED Nijmegen, The Netherlands. E-mail: j.cornelissen@science.ru.nl; a.rowan@science.ru.nl; Fax: (+31) 24365 2929; Tel: (+31) 243652323

\section{Notes and references}

* Mono hydroxy-functionalized tritolylporphyrin 1 was functionalized with the initiator group by stirring it for $30 \mathrm{~min}$ in dry dichloromethane with a small excess of 2-bromoisobutyryl bromide in the presence of an equimolar amount of triethylamine. Insertion of the desired metal was achieved by refluxing this compound in a mixture of methanol-chloroform $(1: 1, \mathrm{v}: \mathrm{v})$ with the corresponding metal(II) bromide. The conversion of styrene during the polymerization was followed by GC. Anisole was used as a standard.

1 A. P. H. J. Schenning, M. C. Feiters and R. J. M. Nolte, Tetrahedron Lett., 1993, 34, 7077; J.-H. Fuhrhop, U. Bindig and U. Siggel, J. Am. Chem. Soc., 1993, 115, 11036.

2 (a) N. S. Cameron, M. K. Corbierre and A. Eisenberg, Can. J. Chem., 1999, 77, 1311; (b) M. Antonietti and S. Förster, Adv. Mater., 2003, 15, 1323.

3 (a) V. Coesens, T. Pintauer and K. Matyjaszewski, Prog. Polym. Sci., 2001, 26, 337; (b) K. Matyjaszewski and J. Xia, Chem. Rev., 2001, 101, 2921

4 (a) G. Deng and Y. Chen, Macromolecules, 2004, 37, 18; (b) R. Narain and S. P. Armes, Macromolecules, 2003, 36, 4675; (c) D. M. Haddleton and K. Ohno, Biomacromolecules, 2000, 1, 152; (d) L. Ayres, M. R. J. Vos, P. J. H. M. Adams, I. O. Shklyarevskiy and J. C. M. van Hest, Macromolecules, 2003, 36, 5967.

5 J. B. Beil and S. C. Zimmerman, Macromolecules, 2004, 37, 778. It should be noted that in the work of Beil and Zimmerman, 10 equiv. of $\mathrm{Cu}(\mathrm{I}) \mathrm{Br}$ are used for 8 initiator sites. Even if one copper is inserted into the porphyrin (a possibility not studied in the paper), there would still be an excess of copper per initiator (1.1 equiv.) and hence catalysis occurs. In addition, the basicity of the ligand may also play a role in the efficiency of copper insertion, when a stronger ligand is used the copper may not be extracted by the porphyrin.

6 The radical formed upon homolytic cleavage of the carbon-bromine bond must be immediately trapped since no conversion of styrene is observed. From entry 3, Table 1 it appears that a copper-porphyrin does not act as the radical trap; its precise nature is still under investigation. 